\title{
VOGAIS NA AMAZÔNIA PARAENSE
}

\section{Regina CRUZ*}

- RESUMO: Este artigo trata essencialmente de uma apresentação das ações do projeto institucional Norte Vogais vinculado ao Diretório Nacional PROBRAVO. O artigo fornece uma ideia precisa de como a equipe da UFPA vinculada ao PROBRAVO está conduzindo suas investigações sobre a variedade do português falada no Pará. O projeto Norte Vogais conta com amostras de fala de trezentos e dezoito informantes nativos do Pará no seu banco de dados. As descrições sociolinguísticas empreendidas pela equipe da UFPA priorizaram a investigação de três aspectos fonéticos em particular: a) a variação das vogais médias pretônicas; b) a variação das vogais médias postônicas mediais e; c) a nasalidade alofônica. Os resultados obtidos reforçam a hipótese de Silva Neto (1957) de que o Pará compreenderia uma ilha dialetal na classificação de Antenor Nascente entre os dialetos do Norte do Brasil. Com o objetivo de refinar as descrições sociolingüísticas, duas novas ações se impuseram: a) o mapeamento da situação sociolinguística das áreas de contato interdialetal no Pará e; b) a análise acústica do sistema vocálico do português falado na Amazônia Paraense.

- PALAVRAS-CHAVE:Variação linguística. Vogais átonas. Português brasileiro. Região Norte.

\section{Introdução}

Em 2005, um grupo de investigadores decidiu criar um diretório de pesquisa nacional denominado Descrição Sócio-Histórica das Vogais do Português (do Brasil) $^{1}$ - PROBRAVO2 ${ }^{2}$ - com o objetivo de realizar uma investigação multidisciplinar - sociohistórica e linguística - para descrever as realizações fonéticas das vogais nos dialetos do Sul ao Norte do Brasil. O PROBRAVO pretende com os seus estudos investigar: a) como são realizadas foneticamente as vogais no Português do Brasil (PB); b) a base da diversidade de realizações fonéticas das vogais átonas do PB e; c) como os falantes do PB se entendem apesar das diversidades da qualidade vocálica. O PROBRAVO pretende igualmente verificar se é possível explicar essa diversidade gramaticalmente.

* UFPA - Universidade Federal do Pará. Faculdade de Letras. Belém - Pará - Brasil. 66045-580 - regina@ufpa.br

1 Disponível em: <http://relin.letras.ufmg.br/probravo>

2 O PROBRAVO é coordenado por Dr. Marco Antônio de Oliveira (PUCMG) e Dr. Seung-Hwa Lee (UFMG), fazem parte quinze outras instituições nacionais além da UFPA e da própria UFMG que sedia o projeto: PUC-MG, UFU, UNESP, UFPB, USP, UFMT, UFBA, UESB, UNICAMP, UFRJ, UFRGS, UCPEL, UFPEL, UNIR e PUC-RS. 
Considerando a importância do tema - vocalismo átono -, são desenvolvidos projetos em todas as regiões do Brasil. No Pará, as investigações sobre o vocalismo átono do português brasileiro estão sendo conduzidas pela equipe da UFPA ${ }^{3}$ coordenada pela autora do presente artigo.

No caso específico das vogais médias pretônicas, a maior fonte de variação no português do Brasil em termos de vocalismo átono, ainda vigora a divisão dialetal de Antenor Nascente, na qual o Nordeste e Norte apresentariam determinadas variantes, diferentes daquelas do resto do Brasil. Mais especificamente, os dialetos do Norte e Nordeste apresentariam as variantes abertas das vogais médias pretônicas totalmente ausentes nos dialetos do sul. Entretanto, as investigações conduzidas no seio do PROBRAVO tem demonstrado que a questão não é tão simples como parece. De um lado, existem os aspectos estruturais correlacionados ao comportamento dessas vogais, de outro, estão as implicações sociais que se correlacionam não apenas às características dos falantes, mas também à atitude do ouvinte, que, muitas vezes, manifesta um comportamento estigmatizante frente ao falar diferente.

Por essa razão, o conhecimento da realidade de uso das vogais tem implicações positivas, tanto para a perspectiva do conhecimento de falares específicos como para a consolidação da teoria linguística em geral.

Na região Norte, os estudos sobre as vogais átonas foram impulsionados com a entrada da autora do presente artigo e de sua equipe de pesquisa, todos integrantes do projeto Norte Vogais, no Grupo PROBRAVO. Antes do trabalho da equipe do projeto NorteVogais, tem-se o registro de raros estudos sobre o tema na variedade do português falado na Amazônia Paraense (NINA, 1991; FREITAS, 2001).

Para se ter uma ideia precisa de como a equipe da UFPA vinculada ao PROBRAVO está conduzindo suas investigações sobre a variedade do português falada no Pará, na seção seguinte, trazemos uma apresentação geral do Projeto Norte Vogais. Em seguida, detalhamos os procedimentos metodológicos adotados, enfatizando principalmente como se está procedendo na formação do banco de dados do projeto e no tratamento dos mesmos. Os fenômenos analisados, como variação das átonas, sejam pretônicas ou postônicas mediais, e nasalidade alofônica são abordados e discutidos com relação aos resultados obtidos a partir das análises sociolinguísticas da variedade do português regional paraense. Na quarta seção, apresentamos as tendências do português da Amazônia Paraense a partir das descrições sociolinguísticas empreendidas. A última seção descreve as duas novas frentes de atuação do Projeto Norte Vogais oriundas dos resultados sociolinguísticos obtidos. A conclusão retoma de forma sintética os temas aqui abordados.

Portaria ILC/UFPA N. 047/2009. 


\section{Projeto Norte Vogais}

O grupo de pesquisadores da UFPA integrantes do projeto Norte Vogais também tem seus projetos em consonância com os objetivos do PROBRAVO. Até o presente momento sete municípios estão sendo investigados no estado do Pará:Aurora do Pará, Belém, Breves, Bragança, Cametá, Mocajuba e Breu Branco, tanto nas suas zonas rurais quanto urbanas.

De maneira geral, a equipe da UFPA, vinculada ao PROBRAVO, pretende ao mesmo tempo caracterizar o sistema vocálico átono e suas variantes, com base em amostra estratificada e em termos variacionistas, assim como analisar qualitativamente e explicar o processo de variação das vogais médias pretônicas e postônicas não finais no português falado no Norte do Brasil condicionado por fatores internos.

O projeto Norte Vogais, inicialmente, deu prioridade por investigar e formar corpora com amostras de fala das variedades linguísticas do português da Amazônia paraense situadas na zona do português regional paraense na classificação dialetal de Cassique (2006 apud CRUZ, 2012).

Cassique (2006), tomando como base as considerações de Silva Neto (1957), apresenta uma nova divisão dialetal do Pará (figura 1) que está sendo considerada pelos pesquisadores da UFPA ligados ao projeto PROBRAVO e, consequentemente, está na base da escolha das localidades-alvo do presente projeto.

A divisão dialetal do Pará estabelecida por Cassique (2006) considera as várias fases migratórias ocorridas no estado e que foram responsáveis pelas alterações da configuração original da situação sociolinguística da região. A primeira fase corresponde à chegada dos açorianos ao Pará ainda no século XVII, quando o português não conseguia sua implantação definitiva, uma vez que se atesta a situação de língua Franca com o domínio de uma variante do tupinambá, a Língua Geral Amazônica - LGA - (CALDAS et al., 2005).

Segundo Rodrigues (1996), a primeira importante leva de falantes nativos de português chegou à Amazônia apenas no primeiro ciclo da Borracha no século XVIII, são os nordestinos que migraram para a Amazônia seduzidos pelo poder econômico da borracha. Até o final do século XIX, o português falado em todo o Pará foi o resultado do contato direto com a LGA, este português resiste ainda hoje na zona 1, da figura 1.

As cidades fundadas na época do Brasil Colonial, como Belém, Cametá, Óbidos e Soure a título de exemplo, mantêm uma variedade linguística com forte influência da LGA. Exceção feita à região Bragantina (zona 2 da figura 1) que, apesar de englobar a cidade de Bragança (também uma cidade do Pará com fundação histórica), possui uma variedade linguística que sofre forte influência 
do falar nordestino por conta de sua proximidade geográfica com o Maranhão, e portanto registra um contato intenso com a variedade linguística do oeste maranhense.

Nos anos 1970, o português regional paraense sofreu mais uma alteração, quando governos militares incentivaram a migração do sul para a Amazônia, com a abertura da Transamazônica. A migração ocorrida se concentrou no sul e sudeste do Pará, alterando radicalmente o português falado nessas regiões e criando uma outra norma distinta do português regional paraense, cujo reduto é, de acordo com Cassique (2006 apud CRUZ, 2012, p.207), (a) o Médio Amazonas Paraense; (b) a região do Salgado; (c) a Ilha de Marajó; (d) o Nordeste Paraense e (e) a capital paraense - Belém. Portanto, na figura 1 abaixo, visualiza-se a região do português regional paraense (1), do dialeto bragantino (2) e de contato interdialetal (3).

\section{Figura 1 - Mapa das localidades-alvo do Projeto Norte Vogais.}

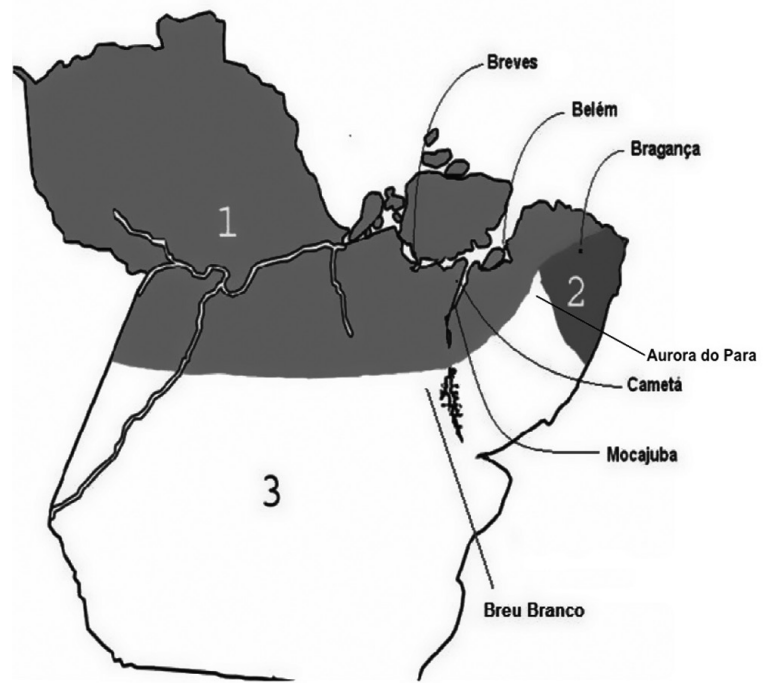

Fonte: Adaptado de Cruz (2012, p.207).

O português regional paraense é também aquele considerado por Silva Neto (1957) como sendo o de canua cheia de cucus de pupa a prua, por conta de sua principal marca dialetal, o alteamento das vogais posteriores em posição de sílaba tônica (RODRIGUES, 2005).

As localidades investigadas e selecionadas para constituirem a área geográfica de atuação do projeto Norte Vogais pertencem ao português regional paraense (Zona 1 da figura 1), Bragança é a única localidade pertencente ao dialeto bragantino (Zona 2 da figura 1), assim como Breu Branco e Aurora do Pará que 
são as únicas localidades investigadas até o momento pertencentes à zona de contato interdialetal (Zona 3 da figura 1).

Desde 2007, quando passou a integrar o grupo PROBRAVO, o projeto Norte Vogais está estudando o processo de variação das vogais átonas de cinco localidades do estado do Pará, a saber: i) do português falado em Cametá (RODRIGUES; ARAÚJJ, 2007; RODRIGUES; REIS, 2012; COSTA, 2010); ii) em Mocajuba (CAMPOS, 2008); iii) em Breves (CASSIQUE et al., 2009; DIAS; CASSIQUE; CRUZ, 2007); iv) em Belém (SOUSA, 2010; CRUZ et al., 2008) e v) em Breu Branco (MARQUES, 2008; COELHO, 2008; CAMPELO, 2008). Todas são descrições sociolinguísticas de cunho variacionista, que, portanto, apresentam um tratamento quantitativo dos dados. Essas análises seguiram orientações metodológicas comuns, desde a formação de seu corpus até o estabelecimento dos fatores a nelas serem considerados, com a finalidade de possibilitar uma comparação de seus resultados quanto ao fenômeno estudado, no caso, as vogais átonas. São justamente estes procedimentos que passaremos a detalhar na seção subsequente.

\section{Procedimentos metodológicos adotados}

As amostras de fala, que compõem o banco de dados do Projeto Norte Vogais, foram coletadas em trabalho de campo, com gravações em áudio. Para a coleta de dados, priorizaram-se as narrativas de experiência pessoal nos moldes da teoria da variação (TARALLO, 1988). Utilizou-se para cada variedade investigada uma amostra estratificada em sexo, faixa etária (15 a 25 anos; 26 a 45 anos e acima de 46 anos) e escolaridade (Analfabeto, Fundamental, Médio e Superior).

Uma vez as gravações concluídas, os dados obtidos foram transcritos grafematicamente observando os parâmetros da Análise da Conversação (CASTILHO, 2003).

Um arquivo contendo a triagem dos dados, tomando como unidade de análise o grupo de força como estabelecido por Câmara Jr. (1969), foi criado, por informante. Uma cópia do mesmo foi feita, para nela se proceder à transcrição fonética do vocábulo contendo o fenômeno estudado. Utilizou-se para a transcrição fonética 0 alfabeto SAMPA4

Uma vez a transcrição fonética concluída, procedeu-se à codificação dos dados. Foram examinados os mesmos grupos de fatores para todos os estudos das variedades do estado do Pará do PROBRAVO5 .

\footnotetext{
4 Disponível em: <http://www.phon.ucl.ac.uk/home/sampa/index.html>

5 Este arquivo de Especificação é de autoria de Orlando Cassique e Doriedson Rodrigues.
} 
O arquivo de especificação utilizado contém grupos de fatores de diversas naturezas: a) fonéticos (natureza da vogal tônica, tipo de ataque da sílaba contendo a vogal-alvo, por exemplo); b) morfológicos (classe gramatical do vocábulo contendo a vogal-alvo); c) sintático (posição do vocábulo no grupo de força), entre outros, além dos fatores sociais também considerados na formação da amostra do corpus. Por último, realizou-se o tratamento estatístico dos dados pelo programa VARBRUL.

\section{Caracterização dos corpora formados}

Os corpora do projeto Norte Vogais possuem um número total de informantes variando de 24 (vinte e quatro) a 72 (setenta e dois), como podemos constatar no quadro 1. Ao todo são 318 (trezentos e dezoito) informantes nativos da Amazônia Paraense, originários de cinco variedades locais: Belém, Cametá, Breves, Breu Branco e Mocajuba, em suas zonas rural e urbana. Como já descrito acima, os informantes que compõem o corpus foram estratificados socialmente em sexo, escolaridade, faixa etária e procedência e a situação de fala predominante é a de narrativas de experiência pessoal. Todo o corpus encontra-se transcrito grafematicamente e com os dados que atestam ocorrência do fenômeno-alvo - vogais médias pretônicas - transcritos foneticamente. Além das transcrições, o corpus contém o áudio das gravações realizadas em trabalho de campo.

Os corpora formados já subsidiaram a produção de 5 (cinco) Dissertações de Mestrado concluídas (CASSIQUE, 2002; RODRIGUES, 2005; CAMPOS, 2008; COSTA, 2010, SOUSA, 2010) e 6 (seis) planos de Iniciação Científica relatados (REIS, 2011; PAIVA, 2010; OLIVEIRA, 2008; DIAS, 2008; OLIVEIRA, 2007), além de 7 (sete) trabalhos publicados (DIAS; CASSIQUE; CRUZ, 2007; RODRIGUES; ARAÚJO, 2007; CRUZ et al., 2008; CASSIQUE et al., 2009; CRUZ, 2010; CRUZ, 2012; RODRIGUES; REIS, 2012). 


\section{Quadro 1 - Número total de informantes de cada amostra utilizada para a investigação do português falado nas localidades estudadas pelo Projeto Norte Vogais com a indicação da fonte de cada estudo realizado.}

\begin{tabular}{|l|l|l|}
\hline \multicolumn{1}{|c|}{ Localidade } & \multicolumn{1}{c|}{ Total de informantes } & \multicolumn{1}{c|}{ Fonte } \\
\hline Breves (urbano) & 42 (quarenta e dois) & Oliveira (2007) \\
\hline Breves (rural) & 36 (trinta e seis) & Dias; Cassique; Cruz (2007) \\
\hline Belém (urbano) & 48 (setenta e dois) & Sousa (2010) \\
\hline Belém (rural) $^{6}$ & 24 (vinte e quatro) & Cruz et al. (2008) \\
\hline Cametá $^{7}$ & 48 (quarenta e oito) & Costa (2010) \\
\hline Mocajuba $^{8}$ & 48 (quarenta e oito) & Campos (2008) \\
\hline Breu Branco $^{24 \text { (vinte e quatro) }}$ & $\begin{array}{l}\text { Marques (2008), Campelo (2008) e Coelho } \\
(2008)\end{array}$ \\
\hline
\end{tabular}

Fonte: Adaptado de Cruz (2010, p.250). 678

O fato de o projeto Norte Vogais ter adotado procedimentos metodológicos comuns na formação de seus corpora e no tratamento dos dados possibilitou o avanço nas descrições sociolinguísticas das variedades investigadas do português falado na Amazônia Paraense, como veremos a seguir.

\section{Fenômenos investigados}

As descrições sociolinguísticas empreendidas pela equipe da UFPA priorizaram a investigação de três aspectos fonéticos em particular: a) a variação das vogais médias pretônicas; b) a variação das vogais médias postônicas mediais e c) a nasalidade alofônica, cujos detalhes serão fornecidos em seguida.

\section{Vogais médias pretônicas}

Nos estudos variacionistas do vocalismo átono do português brasileiro, encontram-se diversos trabalhos que investigam um dado dialeto, tendo como objeto de estudo o comportamento das vogais médias pretônicas. A maioria das pesquisas feitas a esse respeito segue orientações labovianas e utiliza dados quantitativos de um corpus representativo do dialeto escolhido, a título de ilustração, podemos citar Bisol (1981), Callou e Leite (1986), Nina (1991), Bortoni-Ricardo et al. (1991), Viegas (1995), Freitas (2001), Schwindt (2002) e Rodrigues (2005).

\footnotetext{
6 O corpus formado da variedade de Belém possui 15 horas, 30 minutos e 57 segundos de gravação (SOUSA, 2010). O corpus formado da variedade de Cametá possui 21 horas, 26 minutos e 6 segundos de gravação (COSTA, 2010)

8 O corpus formado da variedade de Mocajuba possui 25 horas, 49 minutos e 27 segundos de gravação (CAMPOS, 2008)
} 
No presente estudo, buscamos sintetizar apenas os trabalhos referentes à variedade do Norte do Brasil, mais especificamente da Amazônia Paraense de modo que eles nos possam auxiliar em uma visão mais apurada de como esse fenômeno se manifesta na variedade em questão e, assim, verificar a contribuição do projeto Norte Vogais, em particular, para os estudos sociohistóricos das vogais do $\mathrm{PB}$.

O projeto NorteVogais toma como variável dependente, em suas investigações, as vogais médias pretônicas - </e/ $>$ e $</ \mathrm{O} />-$ e suas variantes - alteamento, manutenção e abaixamento -, como melhor ilustrado na figura 2 abaixo.

\section{Figura 2 - Variável das vogais médias pretônicas e suas variantes, objeto de estudo do projeto Norte Vogais.}

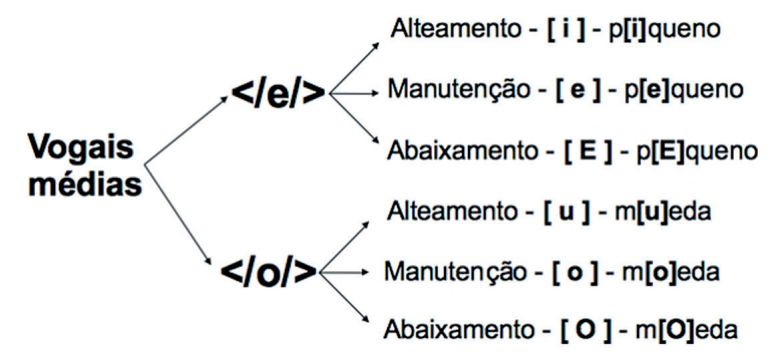

Fonte: Adaptado de Cruz et al. (2012).

O primeiro estudo sobre o assunto de caráter variacionista, envolvendo variedades faladas na Amazônia Paraense, é o de Nina (1991), o qual descreve e analisa o comportamento das vogais médias em posição pretônica na fala de moradores da Região Metropolitana de Belém (PA). Depois de Nina (1991), outros estudos de caráter variacionista se sucederam também, em particular destacaremos os resultados obtidos pela equipe do PROBRAVO na UFPA, a saber: Rodrigues e Araújo (2007), Dias, Cassique e Cruz, (2007), Oliveira (2007), Campos (2008), Marques (2008), Cruz et al. (2008), Cassique et al. (2009) e Sousa (2010).

Rodrigues e Araújo (2007), ao estudarem a variedade do português falada em Cametá (PA), constataram que a presença de vogais nasais propicia o alteamento, seguida da presença de pausa em contexto seguinte, de fricativas glotais, além da presença de vogal alta em posição contígua. Os informantes mais velhos e de menor escolaridade são os que mais realizam o alteamento na variedade observada.

Dias, Cassique e Cruz (2007), em estudo realizado na área rural do município de Breves (PA), tratam igualmente do alteamento das médias pretônicas. Os autores verificaram os condicionamentos dessa variação, muito mais na perspectiva de harmonização vocálica. Os resultados mostraram uma tendência ao não 
alteamento (57\%) em relação ao alteamento (43\%) na variedade investigada. Foi constatado igualmente que a presença da vogal /i/ ou /u/ contígua à sílaba pretônica favorece a aplicação da regra de alteamento, assim como a distância, pois quanto menor a distância maior a possibilidade de ocorrência do fenômeno. No que diz respeito aos fatores sociais, a escolaridade também se mostrou favorecedora da aplicação da regra de alteamento, quanto maior o nível de escolaridade menos probabilidade de ocorrer o alteamento das médias pretônicas, por outro lado a fala dos informantes mais velhos registra uma tendência maior ao alteamento quando comparada a dos mais jovens. A pesquisa também mostrou a presença superior das vogais médias-altas em detrimento das médias-baixas.

Oliveira (2007) analisou dados provenientes de 42 informantes nascidos e residentes do município de Breves (PA). Os dados obtidos a respeito da variável dependente mostraram que a ocorrência de alteamento da vogal média pretônica na área urbana de Breves vem diminuindo consideravelmente. Isso se confirma pelo percentual de alteamento que é de apenas 19\%, enquanto que o de não alteamento é de $81 \%$, portanto em bem mais da metade dos dados, os informantes evitaram o uso de alteamento seja de / o / para [ u ], seja de / e / para [ i ]. Os resultados mostram, ao contrário do que previa Câmara Júnior (1969) no que diz respeito ao ambiente favorecedor do alteamento da vogal média pretônica, que são as vogais tônicas médias (fechadas e abertas) e não altas as que mais favorecem a elevação das vogais médias pretônicas, principalmente quando esta é posterior fechada [o]. Nenhum fator social foi selecionado pelo programa, uma vez que, de um modo geral, todos os falantes evitam o uso das variantes altas.

No estudo de Campos (2008), realizado a partir de dados coletados de 48 informantes no município de Mocajuba (PA), foi constatado que: a) a vogal alta /i/ na tônica como favorecedora do alteamento; b) vogais altas em posição contígua à sílaba tônica aumentam a possibilidade de ocorrência do alteamento; c) a presença de onset vazio favorece o alteamento, além de mostrar que o fenômeno ocorre em maior proporção na fala daqueles que possuem menor escolaridade. Campos (2008) constatou igualmente que, no caso das médias pretônicas da variedade de Mocajuba, atesta-se uma situação de variação estável.

Marques (2008) trata do alteamento das vogais médias em posição pretônica na variedade linguística do português falado no município de Breu Branco (PA). No total, identificaram-se 824 ocorrências do fenômeno estudado. Os resultados mostraram que, no caso das vogais médias anteriores, a presença de nasalidade, de vogal contígua alta, de onset vazio tanto na sílaba-alvo quanto na sílaba seguinte, assim como as sílabas leves favorecem o alteamento. As vogais médias pretônicas posteriores têm maior probabilidade de altear, quando: (a) há a presença da nasalidade, (b) a vogal contígua for alta e c) o onset for vazio. Dos grupos de fatores sociais, foi constatado que os mais velhos e menos escolarizados alteiam 
mais em relação aos mais jovens e escolarizados. Marques (2008) mostrou que o alteamento das médias em posição pretônica é um fenômeno de pouca probabilidade e está em via de extinção no falar breuense por conta do intenso fluxo migratório na região sudeste do Pará.

Cruz et al. (2008) tratam da harmonização vocálica das vogais médias pretônicas no português falado nas ilhas de Belém (PA), com um corpus de 1.592 ocorrências do fenômeno estudado, coletado de 24 informantes estratificados socialmente. Os resultados obtidos mostraram que a elevação da vogal média pretônica é favorecida: a) por vogais altas na tônica, seja esta oral ou nasal; b) por vogais altas imediatas; c) pelas sílabas com onset vazio seja da sílaba contendo a vogal-objeto seja da sílaba seguinte a esta; d) pelo baixo grau de escolaridade e e) pela maior faixa etária. A análise dos dados mostrou que o alteamento das médias em posição pretônica é um fenômeno estável no falar analisado.

Cassique et al. (2009) tratam do alteamento das vogais médias em posição pretônica na variedade linguística do português falada no município de Breves (PA). O corpus utilizado conta com relatos de experiência de 78 informantes nascidos e residentes na cidade de Breves, dos quais 42 vivem na área urbana e 36 na área rural; esses informantes foram estratificados socialmente. Identificaram-se 7.320 dados do fenômeno estudado. Os resultados obtidos mostraram que a elevação da vogal média pretônica é favorecida: (i) pela proximidade da vogal pretônica em relação à sílaba tônica, (ii) pela ausência de sufixos, (iii) pelas sílabas pretônicas com onset vazio, (iv) pelas sílabas tônicas com onset vazio, (v) pelas sílabas pretônicas leves, (vi) pela proximidade da vogal pretônica em relação a uma vogal tônica alta e (vii) pelo baixo grau de escolaridade, pois os informantes que apresentaram pouca ou nenhuma escolaridade foram os que mais realizaram o alteamento.

Verificou-se também a presença superior de vogais médias fechadas em detrimento das médias abertas, assemelhando o dialeto aos falares do extremo Sul do Brasil. A análise dos dados mostrou que o alteamento das médias em posição pretônica é um fenômeno que está sendo extinto do falar rural e urbano de Breves, por se tratar de uma variável estigmatizada, repercutindo no apagamento e perda desta marca do dialeto local.

Sousa (2010) investigou o fenômeno do alteamento das vogais médias pretônicas /e/ e /o/ no português falado na área urbana da cidade de Belém (PA). Para a análise final, foram submetidos ao programa Varbrul, 1.434 dados: 776 das variantes de /e/ e 658 das variantes de /o/. Os resultados mostraram que, no dialeto em questão, predomina o não alteamento (64\%) das vogais médias pretônicas em detrimento do alteamento (36\%). A análise tomou como base 10 (dez) grupos de fatores linguísticos e 3 (três) grupos de fatores sociais que possivelmente pudessem explicar o fenômeno do alteamento. Destes, o programa só não selecionou 1 (um) grupo dos fatores sociais - sexo - como favorecedor do alteamento. 


\section{Vogais postônicas não finais}

O único trabalho sobre postônicas mediais realizados no seio do PROBRAVO pela equipe da UFPA é o de Costa (2010). A autora verifica o comportamento das vogais médias /e/ e /o/ em posição postônica não final de itens lexicais na área urbana e rural do município de Cametá, Nordeste do estado do Pará, Brasil. O estudo desse fenômeno colaborará para a caracterização do dialeto do município em questão. Como reflexo da posição silábica aqui focalizada, os itens tratados neste trabalho foram somente os vocábulos proparoxítonos.

O corpus foi constituído com amostras de fala de 96 informantes estratificados em sexo, faixa etária, nível de escolaridade e procedência. A coleta dos dados foi realizada através de dois tipos de entrevista: a livre (48 informantes), em que os informantes discorreram livremente sobre suas experiências de vida; e o teste ou nomeação de figuras (48 informantes), que consistiu na identificação de desenhos pelos informantes (interpretados pelo falante como teste de memória). Ao todo foram analisados 2.177 dados no programa Varbrul.

Costa (2010) constatou que o fenômeno de alteamento, com um peso relativo de 0,46, apresenta probabilidade menor de ocorrência do que sua ausência com peso relativo de 0,54 .

Examinou-se, também, que as vogais médias em posição tônica desempenham um papel bastante favorecedor do alteamento da média postônica /o/ em estudo. Dos fatores sociais estudados, a escolaridade e a procedência foram consideradas relevantes para explicar a regra variável de alteamento em Cametá.

Este trabalho apresenta igualmente uma análise qualitativa do comportamento das vogais médias - /e/ e /o/ - postônicas não finais, na variedade do português falada no município de Cametá (PA), as quais apresentam quatro variantes possíveis: manutenção [e]/[o], alteamento [i]/[u], apagamento $[\varnothing]$ e abaixamento $[\mathrm{E}] /[\mathrm{O}]$.

Costa (2010) procede igualmente a uma descrição fonológica das vogais médias postônicas - /e/ e /o/ - não finais no português falado na cidade de Cametá (PA). Mais especificamente, analisa qualitativamente a variação das vogais médias postônicas mediais, de forma a verificar como o ambiente fonético é determinante no comportamento das quatro variantes identificadas, a saber: manutenção (abób[o]ra / velocíp[e]de), alteamento (abób[u]ra / velocíp[i]de), abaixamento (abób[O]ra / cér[E]bro) e apagamento (abób[ø]ra / velocíp[ø]i).

Os contextos fonéticos favorecedores de cada uma das variantes identificadas são explicados à luz da geometria dos traços (CLEMENTS, 2004). Aplica-se particularmente a proposta deWetzels (1991) para explicar a neutralização ocorrida 
com as átonas mediais no PB. De forma geral, os dados confirmam o quadro vocálico proposto por Câmara Jr. (1969) para as vogais átonas mediais do PB.

\section{Nasalidade alofônica}

Outro estudo sobre vogais átonas no escopo do projeto PROBRAVO foi o de Rodrigues e Reis (2012) sobre a nasalidade alofônica na variedade do português falada em Cametá (PA). Os autores compararam seus resultados com os de Cassique (2002), realizados sobre o mesmo fenômeno na variedade do português falada em Breves (PA) e com os de Abaurre \& Pagotto (2002), que estudaram também a nasalidade alofônica em cinco variedades do PB (Recife, Salvador, São Paulo, Rio de Janeiro e Porto Alegre).

O corpus final compreendeu a análise de 2.575 ocorrências do fenômeno identificadas na fala de trinta e seis informantes, estratificados socialmente por sexo, faixa etária, escolaridade e procedência emprestados do corpus de Rodrigues (2005).

A variável dependente investigada compreendeu a ausência vs presença de nasalização na vogal átona seguida de consoante nasal na posição de onset da sílaba seguinte, como ilustrado na figura 3 abaixo.

\section{Figura 3 - Variável dependente da nasalização alofônica e suas variantes. \\ Presença de nasalização}

\section{Ex. [pã'ncla]}

Nasalização

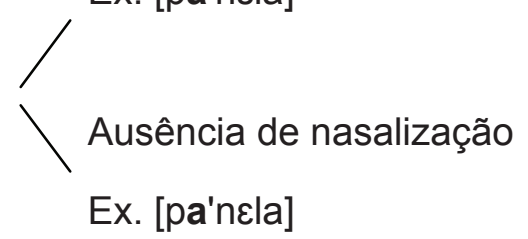

Fonte: Adaptado de Cruz (2010, p.252).

Segundo Câmara Jr. (1969), existem dois tipos de nasalidade: a) uma de natureza fonológica, distintiva, ou seja, a vogal é nasal por união com um arquifonema nasal, são as chamadas vogais nasais verdadeiras (ex.: 'genro' [geNhu] em oposição a 'gero' [g ru]) e; b) outra de natureza fonética (vogais nasalizadas), isto é, a vogal vai ser nasal por efeito de uma assimilação do traço nasal da consoante da sílaba seguinte (ex.: canela> [kãn la]) - como afirma Cagliari (1981), isso diz respeito ao fato de que, seguido de uma consoante nasal, qualquer segmento vocálico tende a ser nasalizado ou não, portanto a nasalidade neste caso é de caráter alofônico. É sobre este último tipo de nasalidade que trata o trabalho de Rodrigues e Reis (2012). 
De acordo com os resultados obtidos em Cametá (PA), há maior probabilidade de ocorrer a variante Presença de nasalização vocálica pretônica, decorrente da assimilação do traço nasal da consoante da sílaba seguinte, em detrimento da variante Ausência de nasalização vocálica pretônica, relacionando o português falado nesse município, em termos de identidade linguística, ao falado em Recife, Salvador e Rio de Janeiro, onde também a presença de nasalização é alta.

O outro trabalho tomado como base de comparação para o fenômeno da nasalidade alofônica é o de Cassique (2002) que estudou o português falado na zona urbana de Breves, nordeste do estado do Pará. Esta pesquisa detectou 2.013 ocorrências de nasalidade alofônica na variedade do português falada em Breves, sendo 1.070 manifestações para a variante nasalizada, consubstanciando um percentual de 53\%, e 943 dados atestando a variante não nasalizada, consubstanciando 47\%. Segundo o pesquisador, os dados evidenciaram que, em Breves, a nasalização de vogais pretônicas antes de consoante nasal na sílaba seguinte era 6\% maior que a não nasalação, o que equivalia, em termos de peso relativo, a 0,54 para a variante presença de nasalação pretônica.

No que diz respeito aos fenômenos investigados relativos ao vocalismo átono, dois achados nos são relevantes, um com relação às vogais pretônicas e outro com relação à nasalidade alofônica, como veremos na seção seguinte.

\section{Tendências do português da Amazônia paraense}

De forma geral, as descrições sociolinguísticas realizadas sobre o português falado na Amazônia Paraense tem demonstrado uma tendência à manutenção das vogais médias em posição pretônica, como expresso no quadro 2.

\section{Quadro 2 - Percentual de alteamento nas variedades linguísticas investigadas pelo Projeto Norte Vogais.}

\begin{tabular}{|c|c|c|c|}
\hline Dialeto & $\begin{array}{l}\text { Não aplicação da } \\
\text { regra }\end{array}$ & $\begin{array}{l}\text { Aplicação da } \\
\text { regra }\end{array}$ & Fonte \\
\hline Breves (urbano) & 81 & 19 & Oliveira (2007) \\
\hline Breves (rural) & 57 & 43 & Dias et al. (2007) \\
\hline Breves (geral) & 67 & 33 & Cassique et al. (2009) \\
\hline Cametá & 60 & 40 & Rodrigues; Araújo (2007) \\
\hline Belém (urbano) & 64 & 36 & Sousa (2010) \\
\hline Belém (rural) & 53 & 47 & Cruz et al. (2008) \\
\hline Mocajuba & 51 & 49 & Campos (2008) \\
\hline Breu Branco & 76 & 24 & Marques (2008) \\
\hline
\end{tabular}

Fonte: Adaptado de Cruz (2012, p.202). 
Outro resultado relevante compreende a inexpressiva ocorrência de vogais médias baixas nas posições átonas. Tais resultados contrariam de um lado a divisão dialetal de Antenor Nascente que caracteriza os dialetos do Norte do Brasil como apresentando uma tendência à realização das vogais médias abertas nas posições átonas, em oposição aos dialetos do Sul do Brasil que prefeririam as vogais médias fechadas. Por outro lado, os resultados reforçam a hipótese de Silva Neto (1957) de que o Pará compreenderia uma ilha dialetal na classificação de Antenor Nascente entre os dialetos do Norte do Brasil (SILVA, 1989), que menciona nos seus resultados uma predominância das vogais baixas no seu corpus formado não somente com amostras de fala do dialeto-alvo - o de Salvador -, que também fôra confrontrado com amostras de fala de 50 pontos do território baiano e de uma localidade do estado de Sergipe emprestadas, respectivamente, do Atlas Prévio dos Falares Baiano e de Mota (1979).

Os resultados dos estudos empreendidos pela equipe do Projeto Norte Vogais têm buscado prioritariamente caracterizar o português regional paraense. Nesse sentido, os resultados sobre as vogais médias pretônicas têm demonstrado uma tendência no uso de suas variantes - alteamento, manutenção e abaixamento - com probabilidade de maior ocorrência de manutenção das médias pretônicas em detrimento do alteamento das mesmas, como constatado no gráfico 1, inclusive com índices percentuais muito próximos de ocorrência da manutenção das médias pretônicas entre as variedades investigadas (Breves (rural), Belém, Cametá e Mocajuba). Duas das variedades investigadas (Breves (urbano) e Breu Branco) confirmam a tendência de manutenção, mas apresentam percentuais muito destoantes das quatro outras variedades comparadas.

\section{Gráfico 1 - Tendência ao não alteamento das vogais médias pretônicas no Português da Amazônia Paraense, de acordo com os resultados dos trabalhos realizados pela Equipe do Projeto Norte Vogais da UFPA.}

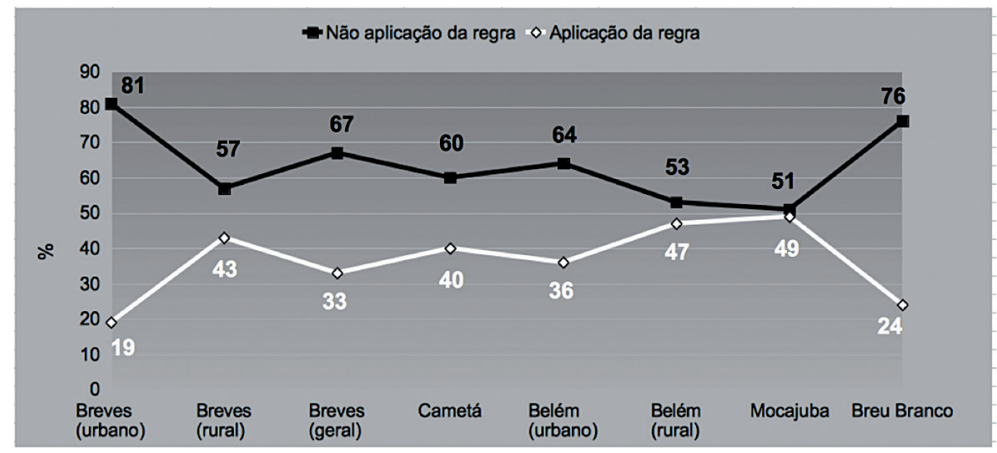

Fonte: Adaptado de Cruz (2012, p.203) 
Os resultados do estudo da variação das médias pretônicas no português da Amazônia Paraense mostram que os percentuais de alteamento são muito baixos de modo geral nas zonas dialetais do Pará.

Os índices mais destoantes de Breves (19\%) e de Breu Branco (24\%), por indicarem a necessidade de uma investigação mais aprofundada sobre a situação sociolinguística destes dois municípios em particular, levaram a equipe da UFPA vinculada ao PROBRAVO a lançar uma nova edição de um outro projeto institucional, o Vozes da Amazônia ${ }^{9}$, destinado a investigar o português falado nas zonas de migração do Pará, como será descrito mais adiante. Breves e Breu Branco apresentam, em comum, o fato de terem sido justamente regiões que receberam um fluxo migratório considerável em decorrência de projetos econômicos da região.

O município de Breves, sozinho, apresenta um terço da população ${ }^{10}$ de todo o arquipélago marajoara. $\mathrm{O}$ inchaço populacional sofrido pelo município se deu no segundo ciclo da borracha, durante a Segunda Guerra Mundial, quando o governo apostando em um crescimento econômico oriundo da borracha, fez vir nordestinos para trabalharem na exploração da borracha na Amazônia, os ditos Soldados da Borracha. Uma vez terminada a guerra e o declínio do segundo ciclo da borracha, os imigrantes nordestinos não tiveram como voltar para a sua terra de origem e fixaram residência obrigatoriamente na Amazônia, uma boa parte deles ficou justamente na cidade de Breves.

Breu Branco é um dos municípios de criação recente no Pará, seus moradores, em sua maioria, são brasileiros originários de diferentes regiões do Brasil - mineiros, paulistas, gaúchos, paranaenses, maranhenses, cearenses, piauienses, tocantinenses - que migraram para o Pará para trabalhar na construção da hidrelétrica de Tucuruí na década de 1980. Com a conclusão da primeira etapa dos trabalhos de implantação da Hidrelétrica de Tucuruí, a maioria desses trabalhadores fixou residência nos municípios da região. Desta forma, a população atual de Breu Branco se assemelha à de Brasília (DF). Breu Branco, portanto, apresenta a mesma situação linguística atestada no DF e no sul do Pará, onde por questões econômicas - no caso, tal situação foi ocasionada pela construção da hidrelétrica - vários dialetos do PB convivem em uma mesma localidade, ocasionando de tal contato dialetal uma nova norma linguística.

Os resultados dos estudos sobre as vogais médias das variedades da Amazônia Paraense demonstraram que estas duas variedades investigadas fogem completamente a uma característica comum das variedades da Amazônia paraense que é a quase neutralização dos pesos relativos referentes à aplicação

9 Portaria N. 075/2009 ILC/UFPA.

10 A população total do município de Breves é de 80.158 habitantes, destes 40.074 habitantes vivem na área urbana, de acordo com o censo 2000 do IBGE. 
e não aplicação da regra de alteamento das médias pretônicas. As variedades de Breu Branco (próximo a Tucuruí) e da zona urbana de Breves (no Marajó) têm como pontos em comum o fato de serem localidades que receberam uma forte migração de falantes do português de outras regiões do Brasil por conta de projetos econômicos. E, neste sentido, elas se assemelham muito às demais variedades da zona 3 da figura 1 de Cassique (2006 apud CRUZ, 2012), pois elas não possuem marcas de identidades (e aí em todos os sentidos) com a Amazônia paraense, e tudo indica inclusive na variedade linguística.

Nossa hipótese é a de que os fatores externos são relevantes no condicionamento da realização das variantes das médias pretônicas e fazem com que tais variedades sejam muito diferentes das demais da Amazônia Paraense. Para comprovar tal hipótese estamos procedendo a uma nova coleta de dados, controlando como principal fator a origem ou ascendência do falante, como fez Bortoni-Ricardo (1985). Acreditamos ser talvez o fator que esteja controlando a realização dessas variantes. Estamos verificando, também, além da variável Origem do Falante, o fator Faixa Etária, em especial, a fala dos mais jovens, a fim de se verificar se é uma variação estável ou mudança em progresso.

Como última hipótese, acreditamos que nas regiões em questão - Breu Branco e Breves - ainda não se cristalizou uma nova norma resultado do contato intervariedades, como ocorrido em Brasília, e o fato desta nova norma ainda não ter sido estabelecida resulta em contraste muito acentuado da realização das variantes atestadas.

Os resultados sobre a nasalidade vêm justamente fortalecer nossa hipótese de sustentação de uma investigação diferenciada para o português falado nas zonas de migração, uma vez que os dados de Breves (CASSIOUE, 2002) contrariam a tendência da nasalidade do português falado no Norte que seria de ocorrência de alto índice de nasalidade.

Comparando-se os resultados de Cametá e Breves com os das cinco capitais brasileiras, presentes em Abaurre \& Pagotto (2002), obteve-se o seguinte quadro de tendência de nasalidade do português brasileiro, como visualizado no gráfico 2 abaixo. 
Gráfico 2 - Tendência da nasalidade alofônica do Norte ao Sul do Brasil (ABAURRE; PAGOTTO, 2002), exceção da região Centro-Oeste, considerando os dados obtidos para Cametá (RODRIGUES; REIS, 2012) e Breves (CASSIQUE, 2002).

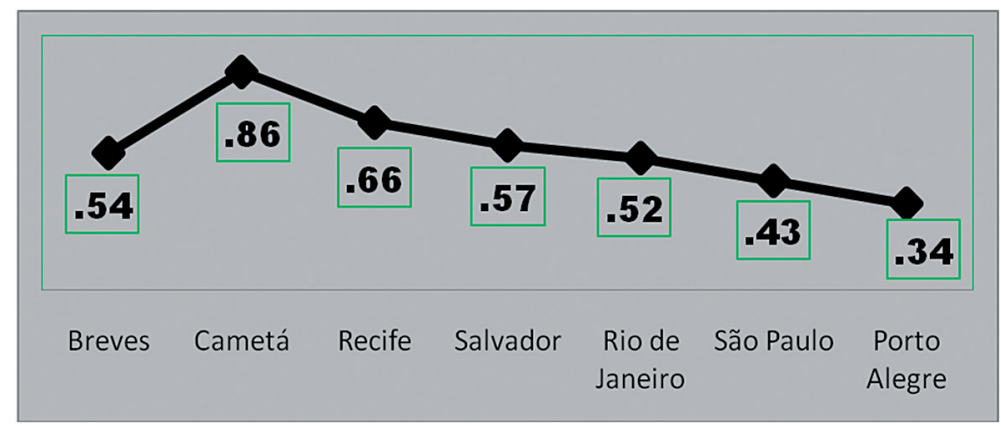

Fonte: Cruz (2010, p.253).

Constata-se, portanto, que há um declínio da nasalidade do Norte ao Sul do Brasil. O índice baixo da variedade de Breves parece não contrariar tal tendência, uma vez que Breves tem indícios de apresentar uma situação sociolinguística particular que levou à elaboração de um projeto de pesquisa específico para investigar o português falado nas regiões formadas em decorrência de forte fluxo migratório, o que será comentado na seção subsequente.

\section{Desdobramentos do Projeto Norte Vogais}

No sentido de precisar ainda mais os resultados alcançados, a equipe da UFPA ligada ao PROBRAVO definiu como ações futuras (CRUZ, 2012):

a) investigação mais aprofundada dos fatores externos como hipótese de serem eles os determinantes nos índices destoantes de alteamento VS manutenção das médias pretônicas no português falado nas localidades de forte fluxo migratório;

b) análise qualitativa e acústica dos corpora de Belém, Mocajuba e Cametá, de modo a precisar se o alteamento das médias pretônicas nessas variedades, quando se dá, é de fato motivado por harmonização vocálica.

São justamente essas ações que passaremos a descrever nesta seção.

\section{Levantamento do português falado nas áreas de migração do Pará}

O objetivo central deste projeto é o de mapear a situação sociolinguística diagnosticada por Cruz (2010) identificada na Amazônia paraense, onde se 
atesta contato interdialetal decorrente de fluxo migratório intenso motivado por projetos econômicos na região Amazônica.

Até o presente momento três regiões foram selecionadas para uma nova fase de investigação do Vozes no estado do Pará: Marabá (MENDES, Projeto de Pesquisa em andamento), Aurora do Pará ${ }^{11}$ (FERREIRA, Dissertação em andamento) e Breves (FAGUNDES, Dissertação em andamento); e duas outras localidades estão previstas: Breu Branco e Parauapebas. Mais precisamente, o Vozes busca identificar a influência de fatores extralinguísticos na configuração dos dialetos da Amazônia paraense, em localidades cujo fluxo migratório é considerável em decorrência de projetos econômicos desenvolvidos na região Amazônica. Na figura 1, estão indicadas as localidades investigadas pelo Vozes da Amazônia.

Para tal, toma como base para a formação do corpus, o conceito de rede social presente em Bortoni-Ricardo (1985), por ser o melhor instrumento para lidar simultaneamente com as diferenças individuais e com a identificação da variação sutil dos padrões sistemáticos e o da análise das redes sociais dos migrantes, já usado anteriormente em sociolinguística correlacional (LABOV, 1972; MIROY, 1980).

O projeto encontra-se vinculado a dois campi da UFPA - o de Belém e o de Marabá - e conta com a infraestrutura destes para a execução de suas atividades. A equipe atual do Vozes da Amazônia, responsável pela condução de suas investigações, é composta por 2 (dois) alunos de Mestrado, 2 (dois) bolsistas de Iniciação Científica e 3 (dois) pesquisadores titulados, todos com vínculo direto com a UFPA, além da coordenadora geral do projeto.

Como o objetivo do Vozes é compor um panorama histórico, antropológico e social do Pará, assim como identificar fatores sociais favorecedores da variação dialetal do português da Amazônia paraense falado nas regiões de forte migração interna, faz-se necessário relacionar aspectos de variação inter e intradialetal. Por essa razão, à medida que se caracteriza sociolinguisticamente o português falado em Marabá, Aurora do Pará e Breves, obtém-se o panorama geral das zonas de migração do Pará.

Assim como Bortoni-Ricardo (1985), utilizaremos o conceito de rede social para as investigações sociolinguísticas envolvendo comunidades linguísticas de migrantes, uma vez que o interesse da investigação não está nos atributos dos indivíduos, mas na caracterização das relações de um com outro, a qual

11 Aurora do Pará fica a $200 \mathrm{~km}$ da capital paraense e localiza-se a nordeste do Pará. Atualmente, possui 26.427 habitantes (IBGE, 2010). Parte de seus habitantes é oriunda de outras cidades, inclusive cidades nordestinas, sobretudo do Ceará, os quais vieram para a região em busca de melhorias e fugindo da seca que assolava a região à época. Isso se deu em meados dos anos 1950-1960. A área total da sede é de $1.812 \mathrm{~km}^{2}$, localizada no Bioma Amazônia. No que se refere ao aspecto histórico, o município recebeu bastantes migrantes nordestinos, sobretudo, do Ceará, e por isso possui características peculiares em sua cultura e língua que diferem em alguns aspectos daquela conhecida por paraense. Aurora do Pará tem sua criação por meio da Lei Estadual n. 5698, de 13 de dezembro de 1991. 
pode predizer e explicar o comportamento destes indivíduos, inclusive o comportamento linguístico.

Por esta razão, para a formação dos corpora consideraremos a noção de grupo de referência dos falantes, como fez Bortoni-Ricardo (1985). Segundo esta autora, o grupo de referência é o grupo que serve de alavanca à construção da identidade do indivíduo, ou seja, o falante modela seu discurso de acordo com o grupo com o qual ele busca identificar-se, com o grupo que atende as suas expectativas psicossociais.

Portanto, para a constituição do corpus, dois grupos de informantes são formados. Um grupo de ancoragem com 24 informantes (12 de cada sexo), distribuídos em duas faixas etárias de 26 a 46 anos e acima de 50 anos. E um grupo de controle de 12 informantes ( 6 de cada sexo), no qual todos devem ter algum grau de parentesco com os membros do grupo de ancoragem, ou seja, devem ser filhos, netos ou sobrinhos dos informantes do grupo de ancoragem.

Uma vez o trabalho de campo concluído, o tratamento dos dados seguirá todas as etapas previstas em um estudo sociolinguístico, a saber: (i) transcrição dos dados nos moldes da análise da conversação (CASTILHO, 2003); (ii) triagem dos grupos de força (CÂMARA JR., 1969); (iii) transcrição fonética dos vocábulos contendo marcas dialetais alvo, utilizando-se o alfabeto SAMPA; (iv) codificação dos dados e (v) tratamento quantitativo VARBRUL.

\section{Caracterização acústica do sistema vocálico da Amazônia paraense}

Como já mencionado anteriormente, no caso das vogais médias pretônicas, todos os resultados sobre as variedades do português da Amazônia paraense apontam para uma tendência dos dialetos paraenses de preferência pela não aplicação da regra de alteamento das médias pretônicas em detrimento do alteamento, como se pode verificar no gráfico 4.

Os estudos também confirmam que quando ocorre o alteamento das vogais médias pretônicas nos dialetos paraenses, o mesmo se dá motivado por uma clara harmonização vocálica, principalmente condicionada pela vogal da sílaba tônica e pela sílaba imediata. Este processo de harmonia vocálica atestado nos dialetos paraenses contempla as hipóteses de Câmara Jr. (1969) e de Silva Neto (1957) ao mesmo tempo. De acordo com Câmara Jr. (1969), o alçamento da pretônica é determinado pela altura da vogal da tônica, um dos fatores mais favorecedores do alteamento das vogais médias pretônicas nos dialetos paraenses. Silva Neto (1957), por sua vez, afirmava ser o alçamento ainda mais favorecido por sílaba com vogal alta contígua e imediata à sílaba da vogal pretônica, o outro fator altamente favorecedor do alteamento das médias pretônicas nos dialetos paraenses. 
Logo, os fatores internos são relevantes para explicar o comportamento variacional das vogais médias nos dialetos da Amazônia Paraense e, em particular, os fonéticos como têm demonstrado os estudos realizados.

Outro resultado relevante compreende a inexpressiva ocorrência de vogais médias baixas nas posições átonas, o que contraria, como já mencionado anteriormente, a divisão dialetal de Antenor Nascente de que os dialetos do Norte do Brasil se caracterizariam por apresentarem uma tendência à realização das vogais médias abertas nas posições átonas.

Diante da particularidade das vogais da Amazônia paraense, neste panorama, optou-se por proceder a um refinamento nas análises empreendidas e, desta vez, por observar mais de perto seus aspectos acústicos.

Por essa razão, atualmente o projeto Norte Vogais está investigando as características acústicas das vogais orais átonas das variedades estudadas da Amazônia Paraense pela equipe da UFPA vinculada ao PROBRAVO ${ }^{12}$.

Inicialmente quatro variedades da Amazônia Paraense - Belém, Cametá, Mocajuba ${ }^{13}$ e Bragança ${ }^{14}$ - estão sendo investigadas com o objetivo principal de analisar acusticamente o seu sistema vocálico tônico e átono. Para tal, formouse um corpus com a mesma estratificação social adotada para as descrições sociolinguísticas: idade, nível de escolaridade ${ }^{15}$, sexo e dialeto. Até o presente momento, o Projeto Norte de Vogais dispõe de um material para análise acústica gravado com 108 informantes ${ }^{16}$.

Cada informante participou de dois protocolos diferentes de coleta de dados: a) um teste de projeção de imagens ${ }^{17} \mathrm{e}$ b) a leitura em voz alta de um texto sobre futebol.

Para a formação do corpus final, foram utilizados na coleta de dados 74 vocábulos selecionados contendo os mesmos contextos controlados pelos estudos variacionistas, como 'bebidas', 'cerveja', 'futebol', 'costurar', 'namorados', 'toalha', a título de exemplo. Utilizamos prioritariamente os vocábulos indicados por

12 A primeira iniciativa de análise acústica para dar conta das necessidades do grupo PROBRAVO foi empreendida por Cruz (2011), em seu estágio pós-doutoral no Departamento de Linguística, da New York University, no período de setembro de 2010 a março de 2011, quando a coordenadora do presente projeto obteve uma bolsa Fulbright/Capes pelo Edital DRI/CGCI N. 027/2009 (processo BEX 1754/10-6) e lá esteve na condição de pesquisadora visitante.

13 Sob responsabilidade de Socorro Campos (UFPA/UFC).

14 Sob responsabilidade de Carlos Nedson (UFPA).

15 Como o protocolo experimental prevê etapa de leitura de texto, os sujeitos analfabetos foram excluídos naturalmente.

16 Sendo 18 nativos da capital paraense, 36 da cidade de Cametá (18 da zona urbana e 18 da zona rural), 36 da cidade de Mocajuba (18 da zona urbana e 18 da zona rural) e 18 da cidade de Bragança.

17 Inspirou-se para a montagem desse teste em Ribeiro (2007) e Costa (2010), que empregaram este mesmo tipo de instrumento de coleta de dados ao estudar as médias postônicas não finais. 
Bisol (1981) contendo vogais pretônicas em contexto de alta variabilidade como 'formiga', 'fogueira', 'bonita', 'menino'.

Aos 108 (cento e oito) sujeitos foi solicitado primeiro que dissessem o que viam logo depois que cada imagem era projetada. A sequência das 70 imagens foi projetada duas vezes a cada participante da pesquisa. A nenhum deles foi revelado, de imediato, os verdadeiros objetivos da pesquisa. Eles tomaram conhecimento dos reais objetivos da pesquisa, apenas quando lhes foi solicitada a assinatura no Termo de Consentimento esclarecido do projeto. Uma vez aplicado o teste de imagens, foi solicitada a leitura de um texto. Foi dado a cada informante um tempo de 10 minutos para familiarização com o tema do texto - futebol - de modo que a leitura fosse a mais natural possível.

Portanto, de cada informante foram obtidos dois tipos de dados, aqueles produzidos por indução com a projeção das imagens e os dados de fala lida. Apenas os dados da variedade de Belém (PA) estão com suas análises mais avançadas sejam os dados obtidos com o teste de imagens (CRUZ, 2011) sejam os dados de fala lida (REIS, 2011; COSTA; SILVA; CRUZ, 2012; CRUZ et al., 2012).

Concluídas todas as etapas anteriores de coleta de dados, procede-se ao tratamento dos dados, que compreende: a) segmentação do sinal de áudio de cada informante no programa PRAAT em cinco níveis; b) extração dos vocábulos-alvo das gravações originais com o programa PRAAT, seguido de codificação deles ${ }^{18}$; c) levantamento das ocorrências das palavras-alvo por informante e por tipo de coleta de dados; d) identificação das variantes ocorridas por vocábulo, considerando os dados de cada informante; e) organização dos dados obtidos em uma planilha Excel para o registro das medidas acústicas tomadas de cada vogal-alvo.

Estão sendo tomadas medidas de F1, F2, F0 e da duração das vogais médias alvo na posição pretônica. As medidas acústicas estão sendo feitas com o auxílio do programa PRAAT. Antes de realizarmos um tratamento estatístico mais robusto, realizar-se-ão tomadas de médias, desvio padrão e teste $\mathrm{T}$ com os valores obtidos para verificação de sua relevância.

As análises dos dados da variedade de Belém (PA) de caráter ainda preliminar têm demonstrado que a variedade do português falada na Amazônia Paraense possui no nível acústico 4 (quatro) variantes para as vogais médias pretônicas: a) alteamento como em fut[i]bol e c[u]madre; b) manutenção como em fut[e]bol e c[o]madre; c) abaixamento como em fut[E]bol e c[O]madre; d) mas há também casos de enfraquecimento das vogais pretônicas ou mesmo

18 Os informantes recebem um código que identifica dialeto, sexo, escolaridade e faixa etária de cada um. Adaptou-se para o presente projeto um código muito semelhante ao código fornecido pelo projeto AMPERPOR: <http://pfonetica.web.ua.pt/AMPER-POR.htm>. Uma vez esse código montado, escreve-se a palavraalvo seguida de seu número de ocorrência no corpus gravado. 
de total desvozeamento destas como em fut[Ø]bol e c[Ø]madre. As análises acústicas têm confirmado os resultados das descrições sociolinguísticas de que a manutenção das médias é a variante de maior ocorrência no português falado na Amazônia Paraense, seguida do alteamento das médias pretônicas, e a variante de abaixamento é a de menor ocorrência nos corpora. Com relação ao nível de escolaridade, os falantes de baixa escolaridade possuem comportamento linguístico no que diz respeito à realização das vogais médias pretônicas distinto dos falantes de alta escolaridade (níveis médio e superior) independentemente do sexo.

Uma análise acústica preliminar já foi realizada com os dados de fala lida, apenas uma tomada de médias dos valores em $\mathrm{Hz}$ de F1 e F2 fora realizada e apesar de ainda estarmos procedendo a um tratamento estatístico descritivo e nenhum tipo de normalização ter sido realizado com os dados, os resultados são relevantes, pois mostram que, no caso das vogais anteriores, tanto na fala masculina quanto na fala feminina a variante alta ocupa quase o mesmo espaço acústico que a variante média fechada e ambas apresentam-se bem distantes da variante baixa. Por outro lado, as vogais posteriores apresentam-se bem discriminadas acusticamente tanto na fala masculina quanto feminina, como podemos constatar na figura 3 abaixo.

\section{Figura 3 - Médias de valores em Hz de F1 e F2 das três variantes das vogais médias pretônicas dos dados de fala feminina (em rosa) e fala masculina (em azul) do corpus de fala lida da variedade de Belém (BE0).}

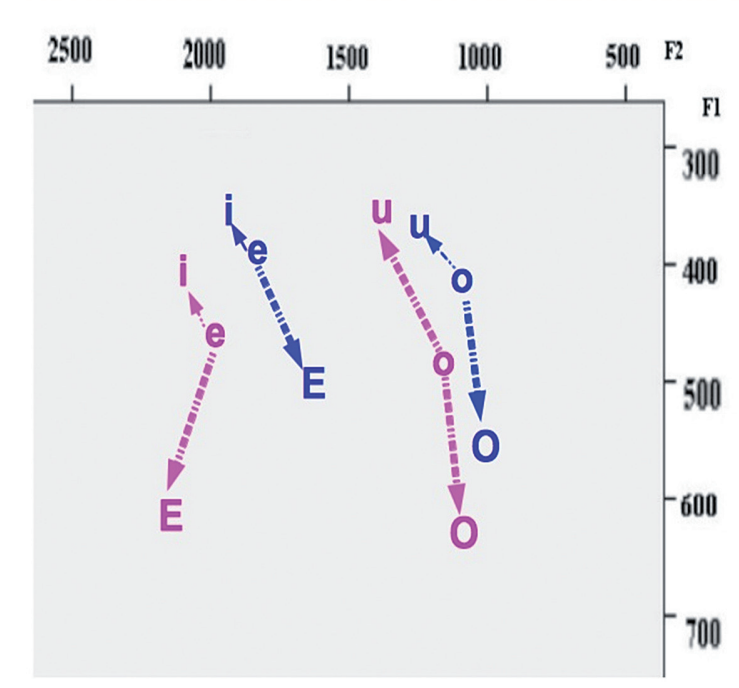

Fonte: Adaptado de Cruz et al. (2012). 
Com o objetivo de tornar mais robustas as análises, futuramente, utilizar-se-á o software R para o tratamento estatístico dos dados.

Com relação ao PROBRAVO em si, a presente proposta pretende contribuir diretamente na implementação de uma metodologia adequada para a análise acústica das vogais médias pretônicas de todas as quinze variedades estudadas pela equipe nacional. Acredita-se, portanto, que as ações aqui propostas poderão constituir modelo para ações nacionais mais contundentes e amplas, no que diz respeito ao tema em questão.

A principal meta é a implementação de uma metodologia adequada para a análise acústica das vogais médias pretônicas de todas as quinze variedades estudadas pela equipe nacional do PROBRAVO.

O outro trabalho de que se tem conhecimento sobre o assunto, apesar de mais voltado para as características acústicas da vogais tônicas, utilizou dados artificiais e não existentes no sistema português como um todo (ESCUDERO et al., 2009). Portanto, a presente proposta prioriza uma análise acústica de dados naturais do português.

\section{Conclusão}

Apresentamos neste artigo as ações do Projeto NorteVogais, sediado na UFPA e vinculado ao Diretório Nacional PROBRAVO.

A equipe responsável pelo Projeto NorteVogais atua desde 2007 e já realizou as descrições sociolinguísticas de cinco variedades do português falado na Amazônia Paraense (Cametá, Mocajuba, Breves, Belém e Breu Branco). O emprego de uma metodologia comum permitiu uma comparação dos resultados obtidos que apontou uma tendência do português falado no Pará à manutenção das vogais médias pretônicas. A comparação apontou também para uma possível dominância de harmonia vocálica quando ocorre o alteamento das médias pretônicas determinada por fatores internos. Por último, os resultados demonstraram a necessidade da aplicação de uma metodologia diferenciada na investigação do português falado nas zonas de contato interdialetal no Pará.

Por esta razão, duas novas ações do Projeto Norte Vogais se instalaram: uma responsável por identificar a influência de fatores extralinguísticos na configuração dos dialetos da Amazônia paraense, em localidades cujo fluxo migratório é considerável em decorrência de projetos econômicos desenvolvidos na região amazônica (Projeto Vozes da Amazônia); uma outra ação responsável por proceder a um refinamento nas análises empreendidas e observar mais de perto aspectos acústicos do sistema vocálico do português falado no Pará. Esta última, mais 
avançada, tem confirmado os resultados das descrições sociolinguísticas de que a manutenção das médias é a variante de maior ocorrência no português falado na Amazônia Paraense, seguida do alteamento das médias pretônicas, e a variante de abaixamento é a de menor ocorrência nos corpora.

$\mathrm{O}$ artigo também tratou de outros aspectos ligados ao vocalismo átono do PB: a nasalidade alofônica e as vogais médias postônicas não finais.

CRUZ, R. Vowels in the north of Brazil. Alfa, São Paulo, v.56, n.3, p.935-962, 2012.

- ABSTRACT:This work deals with a presentation of Norte Vogais project's actions linked to the PROBRAVO team. This paper gives a clear idea of how the UFPA team has been conducting its research about Brazilian Portuguese spoken in Amazon. The Norte Vogais project database has samples of 318 native speakers from Pará. The sociolinguistic descriptions prioritized the research of three phonetic aspects: a) unstressed mid vowels variation in pretonic position; b) unstressed mid vowels variation in post-tonic position and; c) allophonic nasalization. The results reinforce Silva Neto's hypothesis (1957) that Pará is a dialectal island in Antenor Nascente's classification in relation to North dialects. In order to precise the sociolinguistic descriptions, two new actions were necessary: a) sociolinguistic situation map of inter dialectal contact areas in Pará and; b) acoustic analysis of the vowel system of Brazilian Portuguese spoken in the Amazon region of Pará.

- KEYWORDS: Linguistic variation. Unstressed vowels. Brazilian Portuguese. North of Brazil.

\section{REFERENNCIAS}

ABAURRE, B.; PAGOTTO, E. Nasalização no português falado no Brasil. In: KOCH, I. (Org.). Gramática do português falado. 2.ed. São Paulo: Ed. da Unicamp, 2002. p.491-515.

BISOL, L. Harmonia vocálica: uma regra variável. 1981. 333f. Tese (Doutorado em Linguística) - Universidade Federal do Rio de Janeiro, Rio de Janeiro, 1981.

BORTONI-RICARDO, S. M. The urbanization of rural dialect speakers: a sociolinguistic study in Brazil. Cambridge: Cambridge University Press, 1985.

BORTONI-RICARDO, S. M.; GOMES, C. A.; MALVAR, E. S. Um estudo preliminar do /e/ pretônico. Cadernos de Estudos Linguísticos, Campinas, v.20, p.75-90, 1991.

CAGLIARI, L. C. Elementos de fonética do português brasileiro. 1981. $192 f$. Tese (Livre de Docência em Linguística) - Instituto de Estudos da Linguagem, Universidade Estadual de Campinas, Campinas, 1981.

CALDAS, R. et al. Possibilidade de interferência da língua geral amazônica na combinação de orações em Urubú-Ka'apór. 2005. Trabalho oral apresentado ao Workshop sobre Linguística Histórica e Línguas em Contato: Línguas Indígenas Brasileiras e de Áreas Adjacentes, Brasília, 2005. 
CALLOU, D.; LEITE, Y. As vogais pretônicas no falar carioca. Estudos UFBA, Salvador, n.5, p.1-253, dez. 1986.

CÂMARA JR, J. M. Estrutura da língua portuguesa. Petrópolis: Vozes, 1969.

CAMPELO, M. A. Variação das vogais médias anteriores pretônicas no português falado no município de Breu Branco (PA): uma abordagem variacionista. 2008. 50f. Trabalho de Conclusão de Curso (Licenciatura em Letras) - Faculdade de Letras, Universidade Federal do Pará, Belém, 2008.

CAMPOS, S. Alteamento vocálico em posição pretônica no português falado no município de Mocajuba-Pará. 2008. 202f. Dissertação (Mestrado em Letras) -Universidade Federal do Pará, Belém, 2008.

CASSIQUE, O. Minina bunita... olhos esverdeados (um estudo variacionista da nasalização vocálica pretônica no português falado na cidade de Breves/PA). 2002. 90f. Dissertação (Mestrado em Letras) - Universidade Federal do Pará, Belém, 2002.

CASSIQUE, O. et al. Variação das vogais médias pré-tônicas no português falado em Breves (PA). In: HORA, D. (Org.). Vogais no ponto mais oriental das Américas. João Pessoa: Ideia, 2009. p.163-184.

CASTILHO, A. A língua falada no ensino do português. 5.ed. São Paulo: Contexto, 2003.

CLEMENTS, G. N. Feature organization. In: BROWN, K. (Ed.). The encyclopedia of language and linguistics. 2.ed. Oxford: Elsevier, 2004. v.4. p.433-441.

COELHO, M. L. A variação das vogais médias posteriores pretônicas no português falado no município de Breu Branco (PA): uma abordagem variacionista. 2008. $47 \mathrm{f}$. Trabalho de Conclusão de Curso (Licenciatura em Letras) - Faculdade de Letras, Universidade Federal do Pará, Belém, 2008.

COSTA, M.; SILVA, A. C.; CRUZ, R. Análise qualitativa e acústica das vogais médias pretônicas no português falado na Amazônia paraense. In: CONGRESSO INTERNACIONAL DA ASSOCIAÇÃO BRASILEIRA DE LINGUÍSTICA, 2012, Natal. Resumos... Natal: ABRALIN, 2012. p.59-60.

COSTA, R. Descrição sociolinguística das vogais médias postônicas não-finais /o/ e /e/ no português falado no município de Cametá-PA. 2010. 100f. Dissertação (Mestrado em Letras) - Curso de Mestrado em Letras, Universidade Federal do Pará, Belém, 2010.

CRUZ, R. Alteamento vocálico das médias pretônicas no português falado na Amazônia paraense. In: LEE, S. H. (Org.). Vogais além de Belo Horizonte. Belo Horizonte: Ed. da UFMG, 2012. p.194-220. 
Apagamento de vogais médias pretônicas no português da Amazônia paraense: a quarta variante. In: SIMPÓSIO SOBRE VOGAIS: SIS-VOGAIS, 3., 2011, Porto Alegre. Resumos... Porto Alegre: UFRGS, 2011. p.7-11.

Panorama sociolinguístico do português falado na Amazônia paraense. In: SIMÕES, S. (Org.). Navegando entre o rio e a floresta por vias do Marajó: com vista a ensino, pesquisa e extensão. Belém: EDUFPA, 2010. p.243-261.

CRUZ, R. et al. Vogais médias pretônicas no português falado em Belém (PA): análise qualitativa e acústica. In: SEMINÁRIO INTERNACIONAL DE FONOLOGIA. 4., Porto Alegre. Anais... Porto Alegre: Ed. da UFRGS, 2012.

CRUZ, R. et al. As vogais médias pretônicas no português falado nas thas de Belém (PA). In:ARAGÃO, S. (Org.). Estudos em fonética e fonologia no Brasil. João Pessoa: GT-Fonética e Fonologia/ANPOLL, 2008. 1 CD-ROM.

DIAS, M. O alteamento das vogais pré-tônicas /o/ e /e/ no português falado na área rural do município de Breves (PA): uma abordagem variacionista. 2008. Relatório Técnico-Científico de Iniciação Científica, Universidade Federal do Pará, Belém, 2008.

DIAS, M.; CASSIQUE, O.; CRUZ, R. O alteamento das vogais pré-tônicas no português falado na área rural do município de Breves (PA): uma abordagem variacionista. Revista Virtual de Estudos da Linguagem: ReVEL, Porto Alegre, n.9,v.5, p.01-18, jul. 2007. Disponível em:<http://www.revel.inf.br/site2007/_pdf/9/ artigos/>. Acesso em: 27 set. 2012.

ESCUDERO, P. et al. A cross-dialect acoustic description of vowels:brazilian and european portuguese. Journal of the Acoustical Society of America, New York, v.126, n.3, p.1378-1393, set. 2009.

FAGUNDES, G. Alteamento das vogais médias pretônicas no português da Amazônia paraense: a influência do dialeto dos migrantes no português falado em Breves (PA). Belém: Universidade Federal do Pará. (Dissertação em andamento).

FERREIRA, J. E. Mininu, meninu, mEninu: variação das médias pretônicas <e>e $<0>$ no falar de Aurora do Pará - PA: um estudo variacionista. Belém: Universidade Federal do Pará. (Dissertação em andamento).

FREITAS, S. As vogais médias pretônicas no falar da cidade de Bragança. 2001. 96f. Dissertação (Mestrado em Letras) - Universidade Federal do Pará, Belém, 2001.

LABOV, W. Language in the inner city. Philadelphia: University Press, 1972.

MARQUES, L. C. Alteamento das vogais médias pré-tônicas no português falado no município de Breu Branco (PA): uma abordagem variacionista. 2008. 52f. Trabalho de Conclusão de Curso (Licenciatura em Letras) - Faculdade de Letras, Universidade Federal do Pará, Belém, 2008. 
MENDES, S. Vozes da Amazônia: a realização das vogais médias pretônicas na comunidade linguística de Marabá. Marabá: Universidade Federal do Pará. (Projeto de Pesquisa em andamento).

MILROY, L. Language and social networks. Oxford: Basil Blackwell, 1980.

MOTA, J. Vogais antes do acento em Ribeirópolis (SE). 1979. 287f. Dissertação (Mestrado em Língua Portuguesa) - Universidade Federal da Bahia, Salvador, 1979.

NINA, T. Aspectos da variação fonético-fonológica na fala de Belém. 1991. $216 f$. Tese (Doutorado em Língua Portuguesa) - Faculdade de Letras, Universidade Federal do Rio de Janeiro, Rio de Janeiro, 1991.

OLIVEIRA, D. A neutralização das vogais médias pós-tônicas não finais no português falado na área urbana do município de Cametá (PA): uma abordagem variacionista. 2008. Relatório Técnico-Científico de Iniciação Científica, Universidade Federal do Pará, Belém, 2008.

Harmonização vocálica no português falado na área urbana do município de Breves/PA: uma abordagem variacionista. Relatório Técnico-Científico de Iniciação Científica, Universidade Federal do Pará, Belém, 2007.

PAIVA, E. Variação das vogais médias pretônicas no português falado no Norte do Brasil: uma abordagem formal. 2010. Relatório Técnico-Científico de Iniciação Científica, Universidade Federal do Pará, Belém, 2010.

REIS, E. O Sistema vocálico do português falado em Belém (PA): análise experimental. 2011. Relatório Técnico-Científico de Iniciação Científica, Universidade Federal do Pará, Belém, 2011.

RIBEIRO, D. Alçamento de vogais postônicas não finais no português de Belo Horizonte - Minas Gerais: uma abordagem difusionista. 2007. 274f. Dissertação (Mestrado em Língua Portuguesa e Linguística) - Faculdade de Letras, Universidade Federal de Minas Gerias, Belo Horizonte, 2007.

RODRIGUES, A. As línguas gerais sulamericanas. Papia, Brasília, n.4, v.2, p.6-18, 1996.

RODRIGUES, D. Da zona urbana à rural/entre a tônica e a pretônica:alteamento /o/ $>$ [u] no português falado no município de Cametá/Ne paraense: uma abordagem variacionista. 2005. 387f. Dissertação (Mestrado em Letras) - Universidade Federal do Pará, Belém, 2005.

RODRIGUES, D.; ARAÚJO, M. As vogais médias pretônicas / e / e / o / no português falado no município de Cametá/PA - a harmonização vocálica numa abordagem variacionista. Cadernos de Pesquisa em Linguística, Variação no Português Brasileiro, Porto Alegre, v.3, p.104-126, nov. 2007. 
RODRIGUES, D.; REIS, G. Variação da nasalização vocálica pretônica seguida de consoante nasal na sílaba seguinte no português falado no município de Cametá - Pará. In: LEE, S. H (Org.). Vogais além de Belo Horizonte. Belo Horizonte: Ed. da UFMG, 2012. p.322-348.

SCHWINDT, L. C. A regra variável de harmonização vocálica no RS. In: BISOL, L.; BRESCANCINI, C. (Org.). Fonologia e variação: recortes do português brasileiro. Porto Alegre: EDIPUCRS, 2002. p.161-182.

SILVA, M. B. As pretônicas no falar baiano: a variedade culta de Salvador. 1989. 377f. Tese (Doutorado em Língua Portuguesa) - Faculdade de Letras, Universidade Federal do Rio de Janeiro, Rio de Janeiro, 1989.

SILVA NETO, S. Introdução ao estudo da língua portuguesa no Brasil. 4.ed. Rio de Janeiro: Presença, 1957.

SOUSA, J. A variação das vogais médias pretônicas no português falado na área urbana do município de Belém/PA. 2010. 371f. Dissertação (Mestrado em Letras) - Curso de Mestrado em Letras, Universidade Federal do Pará, Belém, 2010.

TARALLO, F. A pesquisa sociolinguística. São Paulo: Ática, 1988. (Série Princípios). VIEGAS, M. C. Alçamento de vogais pretônicas e os itens lexicais. Revista de Estudos da Linguagem, Belo Horizonte, v.2, n.3, p.101-123, 1995.

WETZELS, W. L. Harmonização vocálica, truncamento, abaixamento e neutralização no sistema verbal do português: uma análise autossegmental. Caderno de Estudos Linguísticos, Campinas, n.21, p.25-58, 1991.

Recebido em abril de 2012

Aprovado em julho de 2012 